\title{
SELECTION OF LOGISTICS SERVICE PROVIDERS: CRITICAL ANALYSIS OF METHODS
}

Aleksandrs Kotlars ${ }^{1}$, Mg.oec; Inguna Jurgelane-Kaldava², assoc.professor/ Dr.oec. and Valerijs Skribans ${ }^{3}$, assoc.professor/ Dr.oec.

$$
\text { 1, 2, } 3 \text { Riga Technical University, Latvia }
$$

\begin{abstract}
Different approaches nowadays are used by the companies to systematically compare and evaluate logistics service providers. The purpose of this study is to classify and critically evaluate methods applied to select logistics service providers. This study is organized as follows. Foremost, a systematic literature review was conducted to learn what evaluation methods are applied and how these methods are categorized. Highly ranked literature reviews related to third-party logistics selection problems and multi-criteria decision-making approaches for supplier evaluation and selection were chosen to learn how evaluation methods are categorized by industry leading experts. Second literature review discovered 42 different methods, various combinations of methods and approaches used for the purpose of selection of logistics service provider it was discovered that selection of logistics service provider is classified as multiple criteria decision-making problem. Selection of logistics service provider is a complex process that is often divided into several sub-processes. Each sub-process may require application of individual method. Single methods are not always sufficient to provide solution in scope of the sub-process, hence, combination of methods is often used.
\end{abstract}

Key words: logistics service providers, multiple-criteria decision-making, methodology.

JEL code: L90, M16, R40, R41

\section{Introduction}

To support continuous optimization process of logistics and transportation costs and simultaneously concentrate on core activities, many international businesses outsource part of their logistics functions to logistic service providers, or third-party logistics (3PL). This has become a widely used practice in international business due to wide scope of experience, knowledge and resources of 3PL companies, which allows providing transportation and logistics services at lower costs. As businesses outsource part of logistics and transportation activities, 3PL companies are accurately assessed according to several criteria, which are unique for certain company and industry, e.g. level of prices, scope of available services, responsiveness, financial wealth, reputation. Hence, as a process of strategic decision making, businesses must systematically evaluate 3PL companies according to different criteria, considering both qualitative and quantitative parameters.

Decision-making can be determined as a problem-solving activity that results in an optimal solution. The study of a finite set of alternatives (in this case - logistics service providers) defined in terms of evaluative criteria is an important part of decision-making. If all the parameters are considered at the same time, the job could be to rate these alternatives in terms of how appealing they are to the decision-maker(s). Another task may be to decide the best alternative or the relative overall priority of each alternative (when multiple logistics service providers to be selected) when all parameters are taken into account at the same time. The aim of multiple-criteria decision making is to solve such problems. Figure 1 summarizes general stages of decision-making process. 


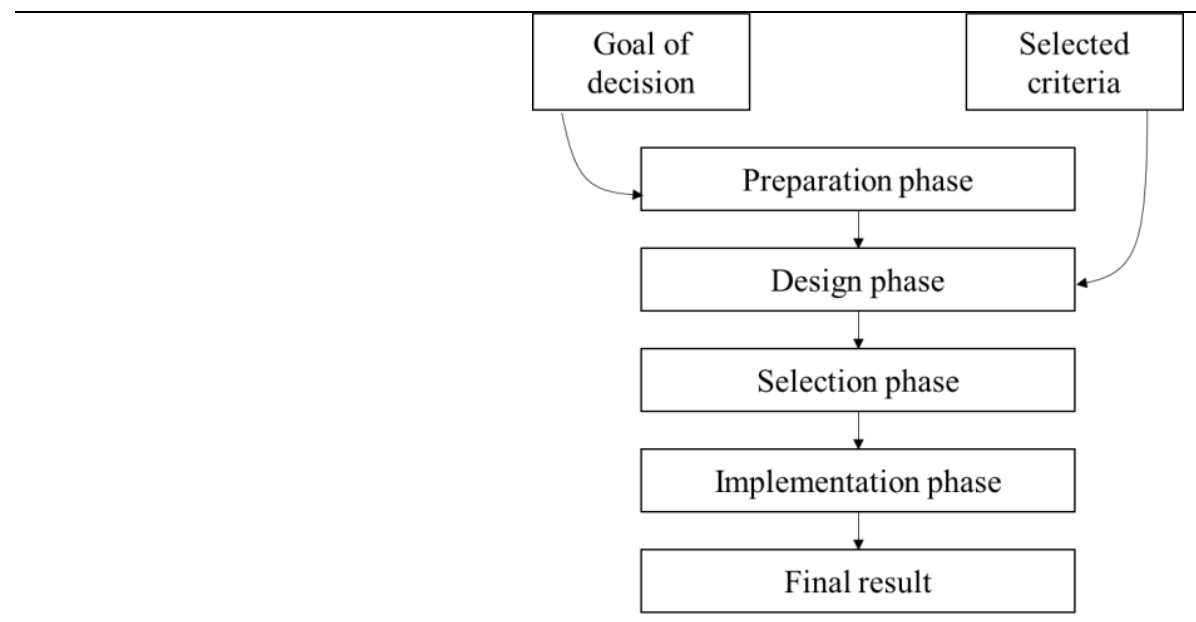

Source: made by authors based on Aguezzoul, 2014

Fig. 1. Decision-making process

The general process is divided into 6 major steps. It begins with definition of decision goal, which is core solution to be taken by the company, and definition of selection (or evaluation) criteria. The next step in the process is preparation phase, when usually market screening is performed to learn about available alternatives. In scope of design phase, a selection process itself is planned, that is followed by selection phase. In this paper, a specific attention to be paid to selection phase, and particularly to methods and approaches used to perform evaluation of logistics service providers. Eventually, decision-making process is complete by implementation phase. In the next section of this paper a detailed review of logistics service providers' selection will be described.

\section{Research results and discussion}

\section{Selection of logistics service providers}

The process of selecting logistics service providers is divided into several phases defined by the companies, according to their practices and their needs. Figure 2 summarizes stages that are typical for most companies.

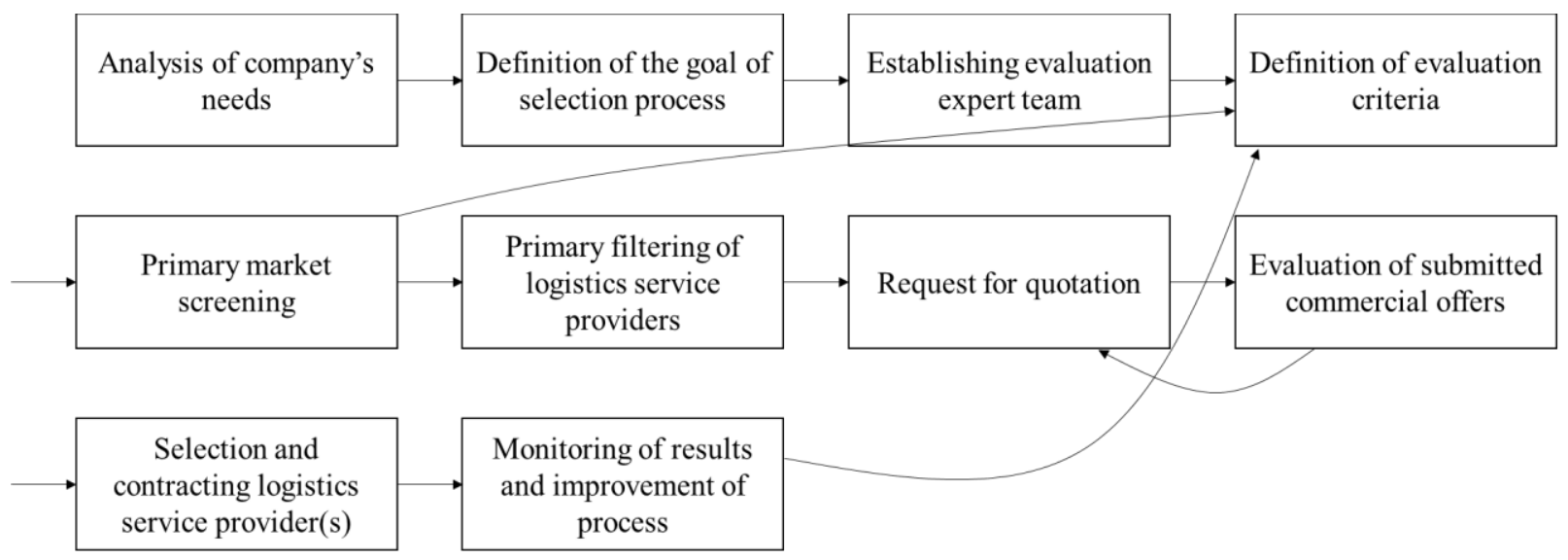

Source: made by authors based on Aguezzoul, 2014; Govindan et al., 2015 and Jayaram et al., 2010

Fig. 2. Logistics service provider's selection

- The selection process starts with analysis of company's needs. The definition of an existing problem for the company, the desired results to be achieved to improve logistics processes.

- Definition of the goal of selection process is a step where the objectives of the selection process are defined. 
- Establishing evaluation expert team involves a group of people at the company to make the selection and assessment of logistics providers.

- Definition of evaluation criteria is next step of the process. These criteria will be integrated in chosen evaluation method.

- Primary market screening helps to determine whether predefined targets and evaluation criteria correspond to market conditions and the capabilities of logistics service providers. Evaluation criteria may be adjusted according to the results of the primary market screening.

- Primary filtering of logistics service providers helps to identify logistics service providers to be invited to the selection process (a tender).

- Request for quotation. A tender has been launched in which pre-selected logistics service providers have been invited.

- Evaluation of submitted commercial offers. Commercial offers are evaluated according to specific methods. The preceding stage shall be repeated, if necessary, by the next round of the tender.

- Selection and contracting logistics service provider(s). According to the needs of the company, logistics service providers are selected, and cooperation agreements are concluded.

- Monitoring of results and improvement of process. Quality indicators are regularly reviewed to track the eligibility of the selected logistics service providers for the contractual conditions. As a result of constant monitoring, companies may choose to adjust evaluation criteria for future requests for quotations.

\section{Review of the methods used for selection of logistics service providers}

Nowadays there is a significant number of scientific researches available from different authors suggesting different approaches to solve decision-making problem related to logistics service provider's selection. Aguezzoul (2014) proposed classifying selection methods according to 5 main categories: multi-attribute decision-making (MCDM) techniques; statistical approaches; artificial intelligence techniques; mathematical programming models; and integrated approaches. Govindan et al. (2015) proposed classifying selection methods according to 3 main categories: multi-criteria decision-making individual methodology; Multi-criteria decision-making integrated methodology; and environmental criteria-based supplier selection. Ho et al. 2010 proposed classifying selection methods according to 2 main categories with several sub-categories: individual approaches (data envelopment analysis, mathematical programming-based approaches, analytical hierarchy process (AHP)-based approaches); integrated approaches (integrated AHP-based approaches, integrated fuzzy approaches, and other integrated approaches). To collect information about entire variety of methods and prepare classification according to authors' need, a systematic literature review was conducted. Search (filtering) process is described in figure 3.

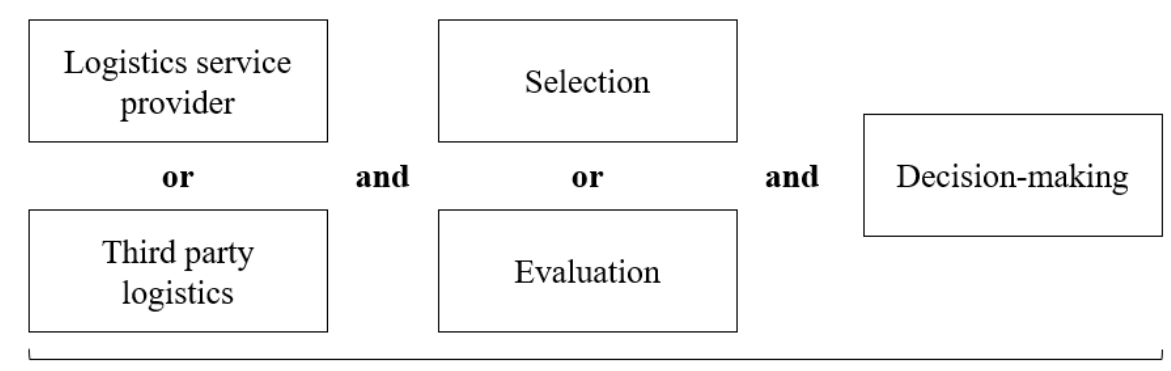

Year published $2016-2020$ (highest citation rate)

\section{Source: made by authors}

Fig. 3. Literature search process 
It was decided to choose original articles published in SCOPUS, addressed to describe process of logistics service provider's selections as a part of multiple-criteria decision-making process. It is important to define filtering criteria so search results reflect selection methods applied specifically for logistics service providers or third-party logistics companies. In fact, selection or evaluation processes satisfy needs of this research, so it was decided to keep both. Finally, it is important to emphasize that selection or evaluation is actually part of decision-making process. To collect actual information, only articles published from 2016 until 2020 were chosen and list methods indicated by authors was created (general list of applied methods). As a result of coding process or key wording (figure 4), a list of unique methods (total list of key words) was created.

\section{Source: made by authors}

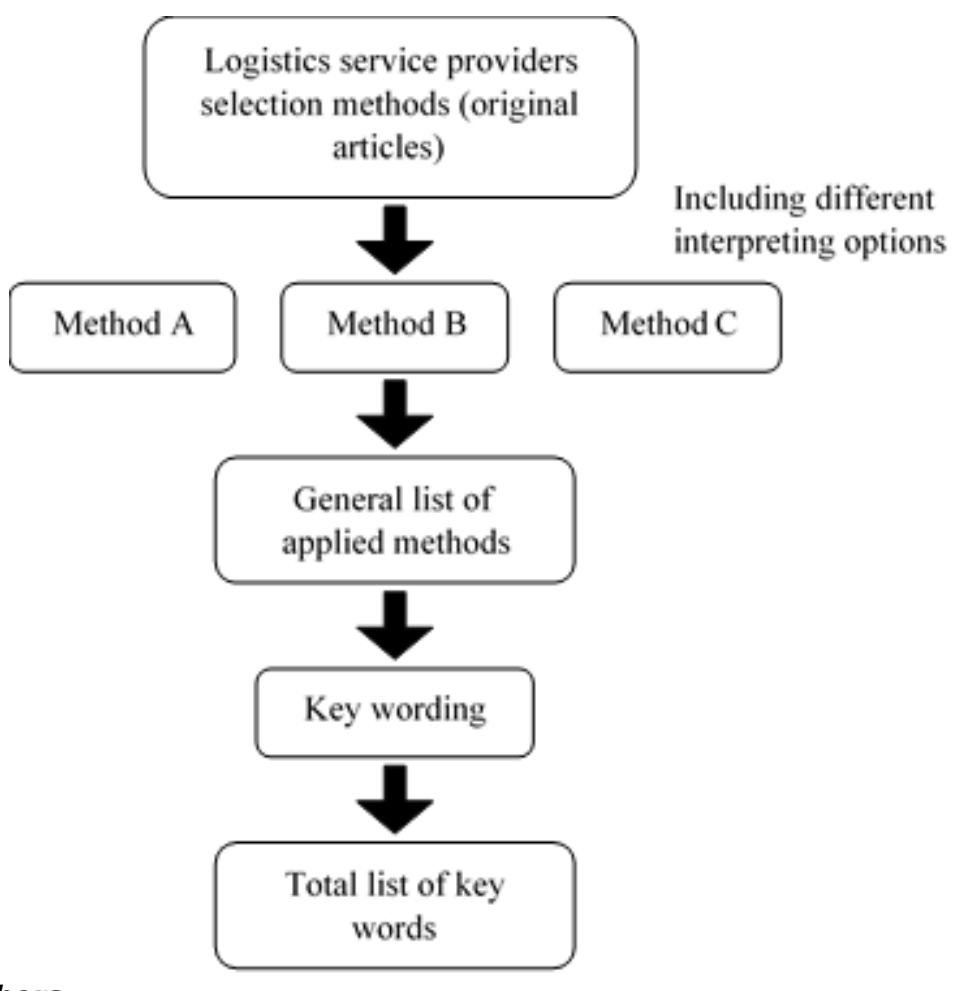

Fig. 4. Revision of selection methods

As shown in figure 4, a revision process begins with review of original articles related to logistics service provider's selection methods. All unique methods and techniques used by authors are noted and extracted from article. It is also important to note that not all listed techniques are standalone and can be used in combination with other methods. The next step of revision is preparing a general list of applied methods. Due to the fact that particular article may contain different methods, quantity of methods in the list exceeds total number of articles reviewed. The next step of revision is key wording that is required because different authors prefer to name same methods differently, so for the purpose of this research, unified naming's are needed. Finally, total list of key words in prepared. Table 1 below shows an entire list of unique methods and tools used to solve a decision-making problem related to logistics service providers selection. In fact, not only standalone methods were chosen (such as AHP, TOPSIS or ANP), but also techniques (fuzzy logic, rough numbers, grey systems) that are used in combination with different methods (integrated approach). This table shows popularity of method or technique among authors, as number of mentions among all selected scientific researches. 
Summary and popularity of applied methods

\begin{tabular}{|l|c|c|c|}
\hline Method or technique & Number of mentions & Share, \% & Cumulative share, \% \\
\hline AHP & 19 & 16.24 & 16.24 \\
\hline Fuzzy & 18 & 15.38 & 31.62 \\
\hline TOPSIS & 12 & 10.26 & 41.88 \\
\hline ANP & 6 & 5.13 & 47.01 \\
\hline DEA & 5 & 4.27 & 51.28 \\
\hline Rough numbers & 4 & 3.42 & 54.70 \\
\hline Best-worst method & 3 & 2.56 & 57.26 \\
\hline Linear programming & 3 & 2.56 & 59.83 \\
\hline WASPAS & 3 & 2.56 & 62.39 \\
\hline COPRAS & 3 & 2.56 & 64.96 \\
\hline Linguistic term set & 3 & 2.56 & 67.52 \\
\hline DEMATEL & 2 & 1.71 & 69.23 \\
\hline SWARA & 2 & 1.71 & 70.94 \\
\hline ISM & 2 & 1.71 & 72.65 \\
\hline Grey systems & 2 & 1.71 & 74.36 \\
\hline VIKOR & 2 & 1.71 & 76.07 \\
\hline Graph theory & 2 & 1.71 & 77.78 \\
\hline MABAC & 2 & 19.41 & 80.34 \\
\hline TODIM & 2 & & 100.00 \\
\hline Other & 2 & & \\
\hline
\end{tabular}

\section{Source: made by authors}

As it is seen from table 1. commonly used standalone methods are Analytical hierarchy process (AHP). Technique for order performance by similarity to ideal solution (TOPSIS). Analytical network process (ANP). Data envelope analysis (DEA) and Best-worst method (BWM). Such techniques as fuzzy logic rough numbers and grey systems commonly used in addition to previously mentioned methods (integrated approach). It was chosen to study these methods in detail to understand practical application to solve logistics service provider selection problem.

As a result of this analysis. It was discovered. That selection of logistics service provider cannot be done by applying single method due to specific of selection process. Many authors admit that there is need to split selection process into sub-activities that. A summary of application of particular method and area of application (sub-activity) is described in table 2 . 


\section{Application of selection methods}

\begin{tabular}{|c|c|c|}
\hline Methods & Practical application & $\begin{array}{l}\text { Sub-activity of } \\
\text { selection } \\
\text { process }\end{array}$ \\
\hline $\begin{array}{l}\text { Analytical hierarchy } \\
\text { process (AHP) }\end{array}$ & $\begin{array}{l}\text { According to Tavana et al. (2016) intuitionistic fuzzy AHP } \\
\text { can be used to evaluate the relative importance weights } \\
\text { among the criteria and the corresponding sub-criteria. } \\
\text { Afterwards these relative weights are used to produce } \\
\text { local weights for all criteria and sub-criteria. Prakash et } \\
\text { al. (2016) advised using fuzzy AHP for evaluation and } \\
\text { prioritization of selection criteria. Jung in } 2017 \text { used AHP } \\
\text { as a main evaluation framework to help decision-makers } \\
\text { determine the relative importance of each criteria or } \\
\text { alternative. After the description of the selection criteria } \\
\text { of logistics service providers. Bianchini in } 2018 \text { suggests } \\
\text { applying AHP to define weights of selection criteria. } \\
\text { Jovcic in } 2019 \text { determines a set of evaluation criteria and } \\
\text { sub-criteria and finds the relationship between them by } \\
\text { using AHP. According to Ozcan ( } 2020 \text { ). the priority levels } \\
\text { of service providers can be calculated by using these } \\
\text { criteria in the combination of AHP. Finally. Galal in } 2018 \\
\text { and Garside in } 2017 \text { advised AHP as a tool to determine } \\
\text { the importance weight of evaluation criteria. }\end{array}$ & $\begin{array}{l}\text { Evaluation of } \\
\text { selection criteria. } \\
\text { Determination of } \\
\text { importance of } \\
\text { selection criteria. } \\
\text { Setting priority } \\
\text { levels of } \\
\text { alternatives. }\end{array}$ \\
\hline $\begin{array}{l}\text { Technique for order } \\
\text { performance by } \\
\text { similarity to ideal } \\
\text { solution (TOPSIS) }\end{array}$ & $\begin{array}{l}\text { According to Prakash. C. TOPSIS is a suitable method for } \\
\text { the selection and development of reverse logistics } \\
\text { partner. Bai in } 2019 \text {. Haldar in } 2017 \text { and Bianchini in } \\
2018 \text { suggested to apply to achieve the final ranking } \\
\text { results. Nuengphasuk in } 2019 \text { advised this method for } \\
\text { the last process of AHP analysis for comparison with the } \\
\text { conventional AHP. Ozcan in } 2020 \text { calculated priority } \\
\text { levels of service providers using TOPSIS. Galal in } 2018 \\
\text { and Garside et al. in. } 2017 \text { evaluated overall } \\
\text { performance which is measured as closeness coefficient. }\end{array}$ & $\begin{array}{l}\text { Final selection of } \\
\text { alternatives. } \\
\text { Creation of final } \\
\text { ranking results. } \\
\text { Evaluation of } \\
\text { performance of } \\
\text { alternatives. }\end{array}$ \\
\hline $\begin{array}{l}\text { Analytical network } \\
\text { process (ANP) }\end{array}$ & $\begin{array}{c}\text { According to Raut et al. ( } 2018 \text { ). ANP performs the } \\
\text { process of weighting diverse criteria and ranks various } \\
\text { alternatives according to their performance on the basis } \\
\text { of these criteria. Tavana et al. in } 2016 \text { used ANP method } \\
\text { to analyse the relationships among the different } \\
\text { selection criteria and to obtain a weight indicating the } \\
\text { relative importance of each criterion. Jayant in } 2016 \\
\text { claims ANP to be a good tool for structuring the problem } \\
\text { related to options in selection of logistics service } \\
\text { provider. }\end{array}$ & $\begin{array}{l}\text { Determination of } \\
\text { importance of } \\
\text { selection criteria. } \\
\text { Definition of } \\
\text { relationships } \\
\text { among criteria. } \\
\text { Primary selection } \\
\text { of alternatives. }\end{array}$ \\
\hline $\begin{array}{l}\text { Data envelope } \\
\text { analysis (DEA) }\end{array}$ & $\begin{array}{l}\text { Raut et al. } 2018 \text { used DEA method for screening the } \\
\text { maximally efficient logistics service providers. Haldar et } \\
\text { al in } 2017 \text { used DEA to evaluate the efficiency of each } \\
\text { alternative according to the identified criteria. }\end{array}$ & $\begin{array}{l}\text { Market screening } \\
\text { (primary selection } \\
\text { of alternatives). } \\
\text { Final selection of } \\
\text { alternatives. }\end{array}$ \\
\hline $\begin{array}{l}\text { Best-worst method } \\
\text { (BWM) }\end{array}$ & $\begin{array}{c}\text { According to Pamucar et al. in } 2019 . \text { BWM can be used } \\
\text { for computing the priority weights of criteria. Govindan } \\
\text { et al in } 2015 \text { used BWM to evaluate and prioritize } \\
\text { shortlisted criteria. }\end{array}$ & $\begin{array}{l}\text { Evaluation of } \\
\text { selection criteria. } \\
\text { Determination of } \\
\text { importance of } \\
\text { selection criteria. }\end{array}$ \\
\hline
\end{tabular}

\section{Source: made by authors}

\section{Description of main selection methods}

The basic idea behind Technique for order performance by similarity to ideal solution (TOPSIS) is that it is based on the principle of a displaced ideal point from which the shortest distance compromise solution 
can be found. The shortest distance from the (positive) ideal solution (PIS) and the farthest distance from the negative ideal solution (NIS) will be used to rank the alternatives. TOPSIS considers the distances to both PIS and NIS at the same time and ranks them in order of preference based on their relative closeness and a combination of these two distance scales. TOPSIS is a utility-based approach that explicitly compares each alternative using data from evaluation matrices and weights. It is presumed that decision information is given in advance by a team or task group while using TOPSIS.

The analytic network process (ANP) is a broader version of the analytic hierarchy process (AHP) which is used in multi-criteria decision analysis. The ANP's decision-making issues are represented as networks. The ANP offers a general structure for dealing with decisions that does not rely on assumptions about the independence of higher-level elements from lower level elements and about the independence of the elements within a level. ANP employs a network rather than a hierarchy. So there are no levels to define. The ANP emphasizes the idea of influence. The ANP is divided into two parts. The first is a control hierarchy or network of criteria and sub criterion that regulates interactions. The network differs from criterion to criterion and for each control criterion a different super matrix of limiting influence is computed. Finally each of these super matrices is weighted according to the priority of its respective control criterion and the results are synthesized by adding all the control criteria together. When using the ANP a problem is often investigated using a control system that includes: a) benefits, b) costs, c) opportunities, and d) risks, each of which is reflected in the control system.

Data envelopment analysis (DEA) is a decision-making technique that uses the linear programming principle to compare the relative operational efficiency of a group of similar decision-making units with multiple inputs and outputs. The maximum potential output for a given set of inputs is estimated using DEA. which is mainly used in efficiency estimation. The envelopment surface and the effective projection path to the envelopment surface are the two most important components of a DEA model. If the model is output-oriented or input-oriented determines the projection direction to the envelope surface. DEA allows for the identification of effective and inefficient units within a system that considers the outcomes in their context. DEA also offers data that allows of inefficient unit to be compared to its "peer group." or a group of efficient units that are like the units under investigation.

Best-worst method (BWM) is a pairwise comparison-based approach that allows for a systematic comparison process. The approach is used to compare a set of options against a set of decision criteria. The BWM is focused on a pairwise comparison of decision criteria that is done in a systematic way. Following that the decision-maker chooses two criteria: the best criterion and the worst criterion. The best criterion is the one that plays the most significant role in the decision-making process while the worst criterion plays the opposite role. The decision-maker prioritizes the best criterion over all other criteria and prioritizes all criteria over the worst criterion. The best solution is found using these two sets of pairwise comparisons as data.

\section{Conclusions, Proposals, recommendations}

1) The presented paper contains analysis of methodology used to solve decision-making problem related to selection of logistics service providers. A revision of newest scientific researches was conducted to define actual methods and set basis for future studies. A comparison of general decision-making process and adaptation of this process to selection of logistics service providers was made. 
2) Research clearly shows that unique selection method cannot entirely solve this problem and a search for integrated or hybrid approach is needed. This idea is also confirmed by results of literature review that demonstrate various combinations of methods combined in single framework.

3) Comparing current literature review with similar reviews conducted earlier. Several changes are noted. First, there are new methods and combinations of methods and techniques that demonstrated dynamics of this research area. Second. There are more research addressed to solve narrow questions and problematics related to selection of logistics service provider selection e.g. green supplier selection reverse logistics supplier selection. Authors conclude that selection process is being transformed to comply with contemporary trends in supply chain management. Hence it is advised to move from general approach of logistics service provider selection to a targeted approach e.g. focusing on customers' industry specifics or service needs.

4) In next research authors will study a detailed split of logistics service provider's selection process to understand sub-activities in scope of this process. There are many researches available that demonstrate application of methods however there is lack of process studies itself. The goal of such research would be to develop a detailed decision-making framework for logistics industry and find optimal integrated approach.

\section{Bibliography}

1. Aguezzoul, A. (2014). Third-party Logistics Selection Problem: A Literature Review on Criteria and Methods. Omega (United Kingdom). 49. 69-78. DOI:10.1016/j.omega.2014.05.009

2. Bai, C. Sarkis, J. (2019). Integrating and Extending Data and Decision Tools for Sustainable Third-party Reverse Logistics Provider Selection. Computers and Operations Research. 110. 188-207. DOI: $10.1016 /$ j.cor.2018.06.005

3. Bianchini, A. (2018). 3PL Provider Selection by AHP and TOPSIS Methodology. Benchmarking. 25(1). $235-252$. DOI: 10.1108/BIJ-08-2016-0125

4. Bianchini, A. (2018). 3PL Provider Selection by AHP and TOPSIS Methodology. Benchmarking. 25(1). $235-252$. DOI:10.1108/BIJ-08-2016-0125

5. Galal, A., Mostafa, N., Elawady, H. (2018). Supplier Evaluation and Selection for Logistics Outsourcing: A conceptual Framework. Paper Presented at the Proceedings of the International Conference on Industrial Engineering and Operations Management. 2018(SEP) 1881-1889.

6. Garside, A. K., Saputro, T. E. (2017). Evaluation and Selection of 3PL Provider Using Fuzzy AHP and Grey TOPSIS in Group Decision Making. Paper presented at the AIP Conference Proceedings. 1902 DOI: $10.1063 / 1.5010673$

7. Govindan, K., Rajendran, S., Sarkis, J., Murugesan, P. (2015). Multi Criteria Decision Making Aproaches for Green Supplier Evaluation and Selection: A literature review. Journal of Cleaner Production. 98. 66-83. DOI: $10.1016 /$ j.jclepro.2013.06.046

8. Haldar, A., Qamaruddin, U., Raut, R., Kamble, S., Kharat, M. G., Kamble, S. J. (2017). 3PL Evaluation and Selection Using Integrated Analytical Modeling. Journal of Modelling in Management. 12(2). 224-242. DOI: $10.1108 / \mathrm{JM} 2-04-2015-0016$

9. Ho W.Xu. X., Dey, P. K. (2010). Multi-criteria Decision Making Approaches for Supplier Evaluation and Selection: A literature Review. European Journal of Operational Research. 202(1). 16-24. DOI: $10.1016 /$ j.ejor.2009.05.009

10. Jayant, A. (2016). Flexible Decision Modelling of 3PL Using MCDM Based Analytical Network Process (ANP) Approach. Supply chain management: Applications for manufacturing and service industries (pp. 59-98)

11. Jayaram, J., Tan, K. (2010). Supply Chain Integration with Third-party Logistics Providers. International Journal of Production Economics. 125(2). 262-271. DOI:10.1016/j.ijpe.2010.02.014

12. Jovcic, S. Prusa, P. Dobrodolac, M. Svadlenka, L. (2019). A Proposal for a Decision-making Tool in Third-party Logistics (3PL) Provider Selection Based on Multi-criteria Analysis and the Fuzzy Approach. Sustainability (Switzerland). 11(15) DOI:10.3390/su11154236

13. Jung, H. (2017). Evaluation of Third party Logistics Providers Considering Social Sustainability. Sustainability (Switzerland). 9(5) DOI:10.3390/su9050777

14. Nuengphasuk, M., Samanchuen, T. (2019). Selection of Logistics Service Provider for E-commerce Using AHP and TOPSIS: A case study of SMEs in Thailand. Paper presented at the TIMES-iCON 2019 - 2019 4th Technology Innovation Management and Engineering Science International Conference. DOI:10.1109/TIMESiCON47539.2019.9024406

15. Ozcan, E., Ahiskali, M. (2020). 3PL Service Provider Selection with a Goal Programming Model Supported With Multicriteria Decision Making Approaches. Gazi University Journal of Science. 33(2). 413-427. DOI: $10.35378 /$ gujs. 552070 
16. Pamucar, D., Chatterjee, K. Zavadskas, E. K. (2019). Assessment of Third-party Logistics Provider Using Multicriteria Decision-making Approach Based on Interval Rough Numbers. Computers and Industrial Engineering. 127. 383-407. DOI:10.1016/j.cie.2018.10.023

17. Prakash, C., Barua, M. K. (2016). An Analysis of Integrated Robust Hybrid Model for Third-party Reverse Logistics Partner Selection under Fuzzy Environment. Resources. Conservation and Recycling. 108. 63-81. DOI: $10.1016 /$ j.resconrec.2015.12.011

18. Raut, R., Kharat, M., Kamble S., Kumar, C. S. (2018). Sustainable Evaluation and Selection of Potential Thirdparty Logistics (3PL) Providers: An integrated MCDM Approach. Benchmarking. 25(1). 76-97. DOI:10.1108/BIJ05-2016-0065

19. Tavana, M., Zareinejad, M., Di Caprio, D. Kaviani. M. A. (2016). An Integrated Intuitionistic Fuzzy AHP and SWOT Method for Outsourcing Reverse Logistics. Applied Soft Computing Journal. 40. 544-557. DOI: $10.1016 /$ j.asoc. 2015.12 .005

20. Zarbakhshnia, N., Wu, Y., Govindan, K. Soleimani. H. (2020). A Novel Hybrid Multiple Attribute Decision-making Approach for Outsourcing Sustainable Reverse Logistics. Journal of Cleaner Production. 242 DOI:10.1016/j.jclepro.2019.118461 